\title{
EFEKTIVITAS PROGRAM KELUARGA HARAPAN (PKH) DAN DAMPAKNYA TERHADAP RELIGIOSITAS MASYARAKAT PENERIMA BANTUAN DI KABUPATEN SOLOK
}

\author{
Awaludini Marifatullah, ${ }^{1}$ Syamsurizal, ${ }^{2 *}$ Abdul Rahim. A, ${ }^{3}$ Novi Yanti, ${ }^{4}$ Fransiska Riana ${ }^{5}$ \\ ${ }^{1,2,3,5}$ Institut Agama Islam Sumatera Barat Pariaman, ${ }^{4}$ Universitas Sumatera Barat \\ J1. Kolonel Anas Malik By Pass, Kota Pariaman, Sumatera Barat \\ e-mail: diniawalud@gmail.com, syamsurizal.tandikek@gmail.com,rahimabdul22a@gmail.com \\ noviyantizavi@gmail.com, fransiskariana@gmail.com
}

\begin{abstract}
Abstrak: Program Keluarga Harapan (PKH) merupakan program pemerintah yang bertujuan untuk peningkatan kesejahteraan masyarakat. Namun fakta di lapangan menunjukkan bahwa banyak masyarakat yang tidak menggunakannya pada semestinya, sehingga hal tersebut berdampak pada ketidakjujurannya yang berefek pada religiositas dari penerima bantuan. Oleh karena itu, Penelitian ini bertujuan untuk mengukur tingkat efektivitas Program Keluarga Harapan dan meninjau dampak religiositasnya. Jenis penelitian ini adalah penelitian lapangan, dengan metode kuantitatif. Data dalam penelitian ini berasal dari data primer berupa data bantuan Program Keluarga Harapan di kabupaten Solok dan data sekunder dari data Badan Pusat statistik dan Kementerian Sosial. Dua model alat analisis yang digunakan adalah matematika sederhana untuk mengukur tingkat keefektifan dan korelasi product moment dari Pearson. Hasil penelitian membuktikan bahwa dampak bantuan Program Keluarga Harapan dalam pengentasan kemiskinan di Kabupaten Solok dengan predikat $81 \%$ dan berada pada kategori sangat efektif. Namun indikator output pada butir soal pertanggungjawaban bidang keagamaan masih kurang efektif karena kesadaran untuk peningkatan keimanan masih kurang.
\end{abstract}

Kata Kunci : Kesejahteraan, Religiositas, Program Keluarga Harapan

\begin{abstract}
Program Keluarga Harapan $(\mathrm{PKH})$ is a government program that aims to improve the welfare of the community. However, the facts on the ground show that many people do not use it properly, so this has an impact on dishonesty which has an effect on the religiosity of the beneficiaries. Therefore, this study aims to measure the effectiveness of the Family Hope Program and review the impact of religiosity. This type of research is field research, with quantitative methods. The data in this study comes from primary data in the form of assistance data from the Family Hope Program in Solok district and secondary data from data from the Central Statistics Agency and the Ministry of Social Affairs. Two models of analytical tools used are simple mathematics to measure the level of effectiveness and product moment correlation from Pearson. The results of the study prove that the impact of the Family Hope Program assistance in poverty alleviation in Solok Regency with a predicate of $81 \%$ and is in the very effective category. However, the output indicators on the items of responsibility in the religious sector are still less effective because awareness for increasing faith is still lacking.
\end{abstract}

Keywords: Welfare, Religiosity, Program Keluarga Harapan 


\section{PENDAHULUAN}

Dalam pembangunan sebuah Negara, seringkali adanya hambatan dalam pembangunan ini salah satunya adalah masalah kemiskinan. Kemiskinan merupakan masalah publik yang kompleks dan bersifat multidimensional. (Hidayat et al., 2011). Kemiskinan berimplikasi terhadap pendidikan, kesehatan, kemampuan ekonomi serta partisipasi masyarakat dalam sebuah Negara. (Lidiana, 2014)

Islam menganggap kemiskinan sebagai problem kehidupan bahkan sebagai suatu musibah yang perlu dihindari. Untuk menghindari masalah tersebut, umat Islam harus saling membantu dan yang memiliki kelebihan harta sebaiknya mendistribusikan hartanya di jalan Allah SWT.(Zulfadli et al., 2021) Distribusikan pendapatan dalam Islam merupakan penyaluran harta yang ada, baik dimiliki pribadi atau umum (publik) kepada pihak yang berhak menerima yang ditujukan untuk meningkatkan kesejahteraan masyarakat sesuai syariat.(Safri \& Saw, 2021)

Pemerintah Indonesia melalui Kementerian Sosial Republik Indonesia dalam menanggulani kemiskinan ini yaitu sebuah Program Keluarga Harapan (PKH) tujuannya untuk kesejahteraan sosial.(Andira et al., 2018) PKH lebih dimaksudkan kepada upaya membangun sistem perlindungan sosial kepada masyarakat miskin. Para masyarakat miskin bisa menghayati dan menginternalisasikan agamanya, sehingga akan berpengaruh pada segala tindakan dan pandangan hidupnya, yaitu kesejahteraan pada diri masyarakat miskin untuk mendapatkan kehidupan yang lebih baik didalam bermasyarakat.(Farwah, 2013)

Peran Agama dalam masalah kemiskinan tidak pernah direduksi menjadi sekedar simpati dan harapan baik, atau kata-kata penghiburan kosong dengan menekankan masa depan yang lebih baik di masa akan datang.(Darajat, 2016) Religiositas adalah sebuah fenomena yang sedang berkembang. Penelitian yang dilakukan oleh Norris dan Inglehart (2011) menunjukkan bagaimana agama tumbuh terutama dikalangan masyarakat miskin yang tertindas. Perasaan tidak aman, kekurangan makanan, dan kelansungan hidup misalnya menciptakan persemaian bagi agama. Agama dapat berperan dalam mengatasi kemiskinan. Agama tidak hanya menjadi kesadaran moral yang mengingatkan msyarakat menjadi murah hati kepada orang miskin tetapi juga melihat orang miskin sebagai sesama manusia. (Rozalinda, 2015)

Dalam beberapa tahun terakhir penelitian ektensif telah dilakukan untuk mengekplorasi sejauh mana agama dapat berkontribusi terhadap pengurangan kemiskinan(Diyah Tri, Cornelius, 2020), diantara penelitian terkait dengan Bantuan Program Keluarga Harapan, yaitu Pertama, penelitian yang dilakukan oleh Budi Hidayat dari Departemen Administrasi dan Kebijakan Kesehatan FKM Universitas Indonesia dengan judul: Program Keluarga Harapan dan Pemanfaatan Pelayanan Kesehatan Preventif. Hasil penelitiannya terkait dengan pemanfaatan Pelayanan Kesehatan Masyarakat penerima Bantuan 
Program Keluarga Harapan.(Hidayat et al., 2011) Kedua, Penelitian yang dilakukan oleh Edi Suharto dari Program Pendidikan Pascasarjana Spesialis-1 STKS Bandung dengan judul: Program Keluarga Harapan (PKH): Memotong Mata Rantai Kemiskinan Anak Bangsa. Hasil penelitiannya terkait dengan pemberian bantuan Program Keluarga Harapan dapat mengurangi masyarakat miskin dan membuka peluang bagi generasi muda yang telah sarjana serta memberikan pendampingan terhadap dunia kerja. (Suharto, Edi; Thamrin, 2012) Ketiga, penelitian yang dilakukan oleh Nurul Infitah dari Program Studi Pendidikan Ekonomi Fakultas Keguruan dan Ilmu Pendidikan Universitas Jember dengan judul: Efektifitas Program Keluarga Harapan (PKH) di Desa Sumber Kejayan Kecamatan Mayang Kabupaten Jember. Hasil penelitiannya, yaitu Bantuan Program Keluarga Harapan yang diberikan kepada masyarakat Desa Sumber Kejayan Kecamatan Mayang Kabupaten Jember sangat efektif dibidang pendidikan dan kesejahteraan sosial, namun kurang efektif dibidang kesehatan masyarakat. (Infitah et al., 2019) Pada tingkat mikro, peran agama dalam kehidupan sehari-hari mereka yang miskin dan pembentukan norma dan praktik, misalnya ketika religiositas atau bahkan milik agama tertentu, memiliki potensi untuk pengentasan kemiskinan. (Schweiger, 2019)

Selain itu, dengan bantuan yang diberikan kepada masyarakat bertujuan agar berdampak pada kesejahteraannya dan terkhususnya pada aspek religiositas dalam bersyukur dan selalu meningkatkan ibadah kepada Allah Swt. (Syamsurizal, 2021) Namun ada sebagian masyarakat yang mendapatkan bantuan ini tidak menggunakan sesuai dengan tujuan dari Kementerian Sosial Republik Indonesia, (Devita et al., 2021) sehingga terdapat penyalahgunaan dan dari aspek Agamanya kurang jujur dalam menggunakan dana yang diberikan serta berdampak pada kurangnya keimanan dan ketaqwaannya pada Allah SWT. (Marseli et al., 2021).

Dengan adanya keterkaitan antara agama dan kemiskinan ini, masyarakat memiliki religiositas yang tinggi dan mampu melihat segala sesuatunya dengan positif maka hal tersebut akan mempengaruhi bagaimana masyarakat miskin mengevaluasi hidupnya secara keseluruhan, dimana evaluasi tersebut merupakan proses yang harus dilewati untuk mencapai kesejahteraan. (Muliana et al., 2020)

\section{METODE PENELITIAN}

Penelitian ini merupakan jenis penelitian lapangan (Field Research), yaitu penelitian yang bertujuan untuk mempelajari secara intensif tentang latar belakang keadaan sekarang dan interaksi lingkungan suatu unit sosial baik individu, kelompok, lembaga, atau masyarakat yang berada pada objek penelitian. Sumber data pada penelitian ini adalah berupa data primer dan data sekunder. (Syamsurizal, 2021)

Untuk menguji keefektivitasan Program Keluarga Harapan (PKH) menggunakan metode matematik dan statistik sederhana. 


$$
\text { EFektifitas PKH }=\frac{\text { Realisasi }}{\text { Target }} \times 100 \% \quad \text { X } 100 \%
$$

Keterangan:

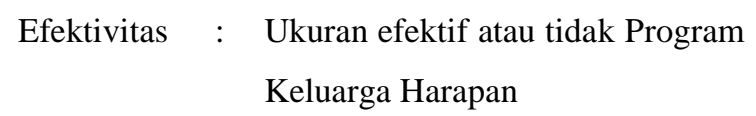

Realisasi : Pencapaian pelaksanaan Program Keluarga Harapan

Penelitian ini menggunakan metode kuantitatif dengan pendekatan deskriptifasosiatif, karena adanya variabel-variabel yang akan ditelaah hubungannya serta tujuannya untuk menyajikan gambaran terstruktur, faktual, dan akurat mengenai fakta-fakta serta hubungan antar variabel terkait dengan bantuan Program Keluarga Harapan (PKH) dan Pengaruhnya terhadap Religiositas Masyarakat pada Kabupaten Solok.

Menurut Drajat mengemukakan, bahwa adanya hubungan positif dan signifikan antara religiositas dengan kesejahteraan subyektif masyarakat miskin. (Setyawan Derajat, 2013). Dalam penelitian kuantitatif, maka membutuhkan pengujian analisis data, sebagai berikut:

Rumus:

$$
r_{x y}=\frac{\sum_{x y}}{\sqrt{\left(\sum_{x}^{2}\right)\left(\sum_{y}^{2}\right)}}
$$

Ket:

$$
\begin{aligned}
& r_{x y}=\text { Korelasi abtar variabel } x \text { dengan } y \\
& x=\left(x_{i}-x\right) \\
& y=\left(y_{i}-y\right)
\end{aligned}
$$

dan dengan rumus:

$$
r_{x y}=\frac{n \sum x_{i} y_{i}-\left(\sum x_{i}\right)\left(\sum y_{i}\right)}{\left(n \sqrt{\left(\sum x_{i}^{2}-\left(x_{i}\right)^{2}\right.}\right)\left(n \sum y_{i}^{2}-\left(y_{i}\right)^{2}\right)}
$$

Untuk menguji keefektivitasan Program Keluarga Harapan (PKH) menggunakan rumus matematik sederhana:
EFektifitas PKH $=\frac{\text { Realisasi }}{\text { Target }} \times 100 \% \quad$ X $100 \%$

Keterangan:

Efektivitas : Ukuran efektif atau tidak Program Keluarga Harapan

Realisasi : Pencapaian pelaksanaan Program Keluarga Harapan

Untuk menguji dampak religiositas terhadap kesejahteraan penerima bantuan Program Keluarga Harapan (PKH) pada masyarakat miskin di Kabupaten Solok digunakan analisis korelasi sederhana digunakan untuk mengetahui derajat korelasi dan besar pengaruh determinasi dari kedua variabel. Analisis korelasi yang digunakan adalah korelasi pearson product moment, dengan rumus :

$$
r_{x y}=\frac{\sum_{x y}}{\sqrt{\left(\sum_{x}^{2}\right)\left(\sum_{y}^{2}\right)}}
$$

Keterangan:

$r_{x y}=$ Korelasi abtar variabel $x$ dengan $y$

$$
\begin{aligned}
x & =\left(x_{i}-x\right) \\
y & =\left(y_{i}-y\right)
\end{aligned}
$$

$$
\mathrm{r}_{\mathrm{xy}}=\frac{\mathrm{n} \sum \mathrm{x}_{\mathrm{i}} \mathrm{y}_{\mathrm{i}-}\left(\sum \mathrm{x}_{\mathrm{i}}\right)\left(\sum \mathrm{y}_{\mathrm{i}}\right)}{\left(\mathrm{n} \sqrt{\left(\sum \mathrm{x}_{\mathrm{i}}^{2}-\left(\mathrm{x}_{\mathrm{i}}\right)^{2}\right)\left(\mathrm{n} \sum \mathrm{y}_{\mathrm{i}}^{2}-\left(\mathrm{y}_{\mathrm{i}}\right)^{2}\right)}\right.}
$$

Kerangka berpikir penelitian ini, dapat digambarkan pada skema berikut:

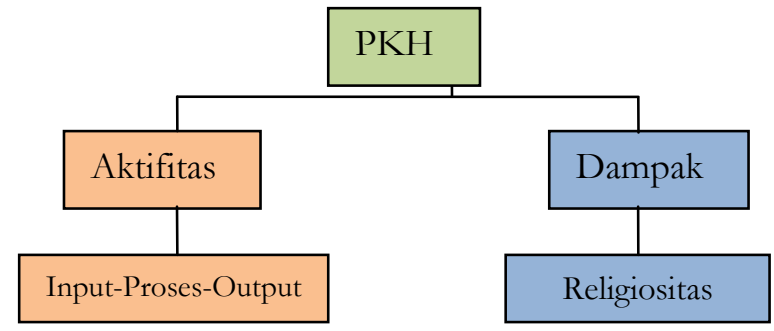

Skema 1: Kerangka Berpikir

Hipotesis merupakan jawaban teoritis sementara terhadap rumusan 
masalah penelitian, belum jawaban empirik. Dengan hipotesis, penelitian menjadi jelas arah pengujiannya dengan kata lain hipotesis membimbing peneliti dalam melaksanakan penelitian di lapangan baik sebagai objek pengujian maupun dalam pengumpulan data. Hipotesis berisi rumusan secara singkat, lugas dan jelas yang dinyatakan dalam kalimat pernyataan. Dikatakan demikian agar hipotesis dapat diuji atau dijawab sesuai dengan teknik analisis yang telah ditentukan. Adapun hipotesis dalam penelitian, yaitu sebagai berikut:

Tabel 1. Hipotesis Penelitian

\begin{tabular}{|c|c|c|}
\hline H1 & : & \begin{tabular}{lrr} 
Program & Keluarga & Harapan \\
$(\mathrm{PKH})$ & sudah & efektif \\
dalam & \multicolumn{2}{c}{ mengentaskan } \\
kemiskinan & masyarakat \\
Kabupaten Solok & \\
\end{tabular} \\
\hline $\mathrm{H} 2$ & : & 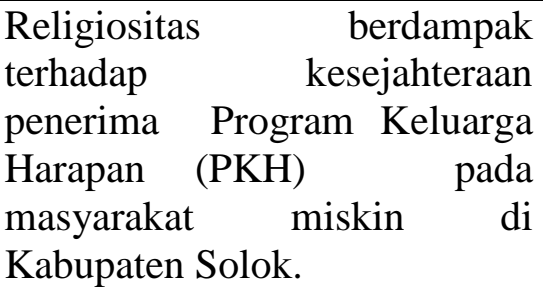 \\
\hline
\end{tabular}

Kemudian adapun sampel dari penelitian ini sebagaimana diterangkan pada tabel berikut:

Tabel 2. Sampel berdasarkan Usia

\begin{tabular}{|c|c|c|}
\hline $\begin{array}{c}\text { Jenis } \\
\text { Usia } \\
\text { (Tahun) }\end{array}$ & $\begin{array}{c}\text { Frekuensi } \\
(\text { Orang) }\end{array}$ & $\begin{array}{c}\text { Persentase } \\
(\%)\end{array}$ \\
\hline$<20$ tahun & 0 & 0 \\
\hline $20-29$ tahun & 5 & 5,38 \\
\hline $30-39$ tahun & 20 & 21 \\
\hline $40-50$ tahun & 48 & 21,5 \\
\hline$>50$ tahun & 20 & 100 \\
\hline Jumlah & $\mathbf{9 3}$ & \\
\hline
\end{tabular}

Tabel 3. Sampel berdasarkan Jenis Kelamin

\begin{tabular}{|c|c|c|}
\hline $\begin{array}{c}\text { Jenis } \\
\text { Kelamin }\end{array}$ & Frekuensi & $\begin{array}{c}\text { Persentase } \\
(\%)\end{array}$ \\
\hline Laki-laki & 1 & 1,08 \\
\hline Perempuan & 92 & 98,92 \\
\hline
\end{tabular}

Tabel 4. Sampel berdasarkan Pekerjaan

\begin{tabular}{|c|c|c|}
\hline $\begin{array}{c}\text { Jenis } \\
\text { Kelamin }\end{array}$ & Frekuensi & $\begin{array}{c}\text { Persentase } \\
(\%)\end{array}$ \\
\hline $\begin{array}{c}\text { Ibu Rumah } \\
\text { Tangga }\end{array}$ & 45 & 48,39 \\
\hline Lainnya & 12 & 12,9 \\
\hline Jumlah & $\mathbf{9 3}$ & $\mathbf{1 0 0}$ \\
\hline
\end{tabular}

Tabel 5. Sampel berdasarkan Pendidikan

\begin{tabular}{|c|c|c|}
\hline $\begin{array}{c}\text { Jenis } \\
\text { Pendidikan }\end{array}$ & $\begin{array}{c}\text { Frekuensi } \\
\text { (Orang) }\end{array}$ & $\begin{array}{c}\text { Persentase } \\
(\%)\end{array}$ \\
\hline $\begin{array}{c}\text { Tidak } \\
\text { Sekolah }\end{array}$ & 31 & 33,33 \\
\hline SD & 29 & 31,18 \\
\hline SMP & 17 & 18,27 \\
\hline SMA & 15 & 16,12 \\
\hline Sarjana & 1 & 1,07 \\
\hline Jumlah & 97 & 100 \\
\hline
\end{tabular}

\section{HASIL DAN PEMBAHASAN}

Program Keluarga Harapan (PKH) adalah program pemberian bantuan tunai bersyarat kepada Keluarga Penerima Manfaat (KPM) yang memenuhi syarat kepesertaan dan ditetapkan oleh kementerian sosial. Menurut Kementerian Sosial Republik Indonesia mengeluarkan kebijakan untuk menanggulangi kemiskinan yaitu sebuah Program Keluarga Harapan (PKH) yang merupakan pelaksaan dari UU No. 11 tahun 2009 Tentang Kesejahteraan sosial.

Program ini diberikan kepada warga 
yang tidak mampu secara ekonomi, dengan tujuan untuk peningkatan kesejahteraan masyarakat, dan hal ini juga merupakan bentuk tanggung jawab pemerintah terhadap warganya.

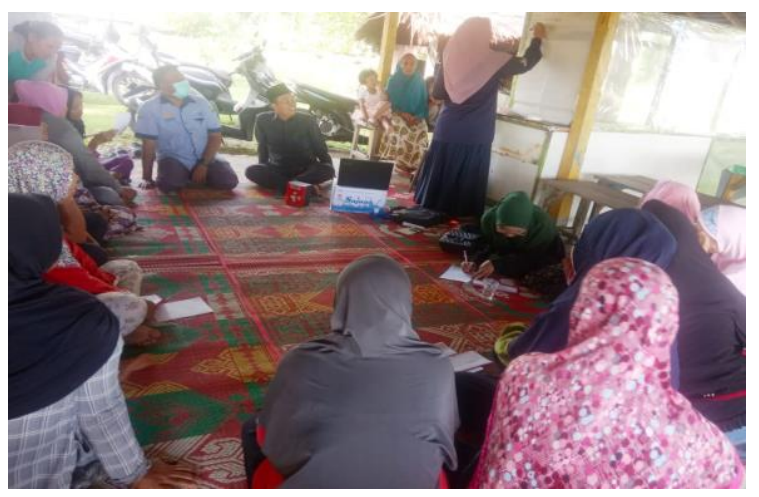

Gambar 1: Sosialisasi Tujuan PKH

Kegiatan program PKH ini bertujuan untuk membangun sistem perlindungan sosial kepada masyarakat miskin dalam rangka percepatan penanggulangan kemiskinan, mempertahankan dan meningkatkan kesejahteraan sosial masyarakat yang berkaitan dengan pendidikan dan kesehatan. Menurut Glock dan Stark, religiositas merupakan tingkat konsepsi seseorang terhadap agama dan tingkat komitmen seseorang terhadap agamanya, (Syamsurizal, 2021) sehingga dengan pemberian bantuan Program Keluarga Harapan kepada masyarakat yang kurang mampu/miskin dapat meningkatkan komitmen dan pengetahuan keagamaannya di setiap pribadi masyarakat tersebut.

Tingkat efektivitas dapat diukur dengan membandingkan antara rencana yang telah ditentukan dengan hasil nyata yang telah diwujudkan. Namun, jika hasil pekerjaan dan tindakan yang dilakukan tidak tepat sehingga menyebabkan tujuan tidak tercapai, maka hal itu dikatakan tidak efektif. Indikator-indikator variabel ini dapat diukur sebagai berikut : Indikator masukan, Indikator proses, Indikator keluaran, Indikator manfaat, dan Indikator dampak.

Kesejahteraan berasal dari kata dasar sejahtera, aman, sentosa, makmur dan selamat atau terbebas dari kesusahan, gangguan dan lain sebagainya. Kesejahteraan berarti suatu keadaan dimana seseorang merasa bahwa dirinya aman, selamat, tentram, senang dan makmur. (Suharto, Edi; Thamrin, 2012)

Menurut Ahmad Zaki Badawi, kesejahteraan adalah keadaan yang mengharuskan tercukupinya kebutuhan dasar bagi individu atau kelompok, semacam kebutuhan makanan, pendidikan, dan kesehatan, sedangkan kesedihan (bencana) adalah kebalikannya. Kemudian menurut Jaih Mubyanto, ia menjelaskan bahwa kesejahteraan adalah sesuatu yang dirasakan oleh individu untuk dapat hidup dengan senang dan tentram, merasa nyaman dalam batasan yang mungkin dicapai oleh setiap individu. Dimana dijelaskan juga bahwa kriteria orang berada dalam status kehidupan yang sejahtera yakni: tercukupinya kebutuhan makan, pakaian, dan rumah yang nyaman, (2) terjaga kesehatan, (3) terpenuhinya pendidikan yang layak bagi anak-anak. Selain itu kesejahteraan juga mencakup unsure batin dimana kesejahteraan didapat dari persaan untuk ingin diperlakukan secara adil dalam hidup.

Religiositas menurut Glock dan Strak adalah tingkat konsepsi seseorang terhadap agama dan tingkat komitmen seseorang terhadap agamanya. Tingkat 
konseptualisasi adalah tingkat pengetahuan seseorang terhadap agamanya, sedangkan yang dimaksud dengan tingkat komitmen adalah sesuatu hal yang perlu dipahami secara menyeluruh, sehingga terdapat berbagai cara bagi individu untuk menjadikan religius. (Sofianto, 2020) Glock dan Stark mengemukakan bahwa agama adalah sistem symbol, sistem keyakinan, sistem nilai, dan sistem prilaku yang terlembagakan, yang semuanya itu berpusat pada persoalan-persoalan yang dihayati sebagai yang paling maknawi (ultimate meaning). (Farwah, 2013)

Dalam Islam, religiositas pada garis besarnya tercermin dalam pengamalan akidah, syariah, dan akhlak, atau dengan ungkapan lain: iman, Islam, dan ihsan. Bila semua unsur itu telah dimiliki oleh seseorang, maka dia itulah insan beragama yang sesungguhnya.(Zakiyah et al., 2020)

Anggasari membolehkan antara istilah religi atau agama dengan istilah religiositas. Agama atau religi menunjuk pada aspek formal yang berkaitan dengan aturan-aturan dan kewajiban-kewajiban, sedangkan religiositas menunjuk pada aspek yang dihayati oleh individu. Hal ini selaras dengan pendapat Dister yang mengartikan religiositas sebagai keberagamaan, yang berarti adanya unsure internalisasi agama itu dalam diri individu. Lindridge menyatakan bahwa religiositas dapat diukur dengan kehadiran lembaga keagamaan dan pentingnya agama dalam kehidupan sehari-hari. Jadi religiositas adalah tingkat pengetahuan seseorang terhadap agama dan menjalankan kewajiban agamanya dengan keihlasan hati.

Sedangkan Program Keluarga harapan $(\mathrm{PKH})$ adalah program pemberian bantuan tunai bersyarat kepada Keluarga Penerima Manfaat yang memenuhi syarat kepesertaan dan ditetapkan oleh kementerian sosial.

Program Keluarga Harapan (PKH) bertujuan :

a. Untuk meningkatkan taraf hidupkeluarga penerima manfaat melalui akses layanan pendidikan, kesehatan, dan kesejahteraan sosial;

b. Mengurangi beban pengeluaran dan meningkatkan pendapatan keluarga miskin dan rentan;

c. Menciptakan perubahan perilaku dan kemandirian keluarga penerima manfaat dalam mengakses layanan kesehatan dan pendidikan serta kesejahteraan sosial; dan

d. Mengurangi kemiskinan dan kesenjangan antar kelompok pendapatan.

\section{Efektivitas Program Keluarga Harapan (PKH)}

Hasil perhitungan untuk tingkat efektivitas Program Keluarga Harapan $(\mathrm{PKH})$ dilihat dari tiga indikator yaitu input, proses, dan output. Pada indikator input terdapat enam sub pertanyaan yang terdiri dari status penguasaan bangunan tempat tinggal, bahan bakar utama untuk memasak, status kepemilikan fasilitas buang air besar, sumber air, sumber penerangan, dan daya penerangan. Indikator input merupakan ketepatan sasaran Program Keluarga Harapan 
(PKH), pada indikator input ini apakah program yang telah diberikan oleh pemerintah ini sudah tepat sasaran diberikan kepada masyarakat yang masuk kedalam kategori penerima Program Keluarga Harapan (PKH). Dari hasil penelitian di temukan bahwa dari sisi input program ini sudah efektif yaitu sebesar $78 \%$, angka ini masuk kedalam kategori cukup efektif.

Indikator kedua yaitu proses pelaksanaan Program Keluarga Harapan $(\mathrm{PKH})$ terdapat empat sub item pertanyaan yang terdiri dari Pertemuan awal dan validasi, pertemuan kelompok bulanan, penyaluran bantuan, pemutakhiran data. Indikator proses pelaksanaan mengenai persepsi KPM terhadap pelaksanaan program, pada indikator proses ini apakah sesuai dengan pedoman umum pelaksanaan PKH yang telah ditetapkan. Dari hasil penelitian di temukan bahwa dari sisi proses pelaksanaan program ini sudah efektif yaitu sebesar $98 \%$, angka ini masuk kedalam kategori sangat efektif.

Selanjutnya indikator ketiga yaitu output Program Keluarga Harapan (PKH) terdapat dua sub item pertanyaan yang terdiri dari kewajiban di bidang pendidikan dan kewajiban di bidang kesehatan. Indikator output mengenai kewajiban dari kelompok penerima manfaat (KPM) yaitu pada pendidikan dan kesehatan. Dari hasil penelitian di temukan bahwa dari sisi proses pelaksanaan program ini sudah efektif yaitu sebesar $67 \%$, angka ini masuk kedalam kategori sangat efektif.

Dari paparan diatas ketahui bahwa dari sisi input, proses, dan output
Program Keluarga Harapan dilakukan perhitungan di peroleh angka $81 \%$, maka program ini masuk kedalam kategori sangat efektif.

\section{Dampak Program Keluarga Harapan (PKH) terhadap Religiositas Penerima}

Untuk analisis korelasi pearson product moment religiositas terhadap kesejahteraan penerima Program keluarga Harapan (PKH), dilihat dari tabel korelasi terdapat angka signifikan sebesar 0,000 artinya apabila nilai signifikansi lebih $<0,05$ maka berkorelasi, sehingga didapat adanya dampak antara religiositas dengan kesejahteraan penerima bantuan PKH. Besar korelasi atau dampak antara variabel religiositas dan kesejahteran penerima Program Keluarga Harapan adalah sebesar 0,875 . Untuk uji signifikansi hubungan antara variabel, maka nilai hitung langsung dikonsultasikan dengan nilai $r$ tabel pada taraf uji 5\%. Nilai $\mathrm{r}$ hitung sebesar 0,875 dan $r$ tabel adalah sebesar 0,207 , ini berarti adanya hubungan antara religiositas dengan kesejahteraan penerima bantuan PKH karena 0,875>0,207.

\section{SIMPULAN}

Tingkat efektivitas Program Keluarga Harapan (PKH) dilihat dari 3 sisi indikator yaitu input, proses pelaksanaan, output. Jadi pada sisi input ini tingkat efektivitas program bantuan PKH sebesar $78 \%$, dan masuk kategori cukup efektif. Dan dilihat dari sisi proses pelaksanaan Program Keluarga Harapan adalah sebesar 98\%, dan masuk kategori sangat efektif. Kemudian dari sisi output tingkat 
efektivitas program adalah sebesar $67 \%$ dan masuk kategori cukup efektif. Dari hasil hasil analisis didapatkan tingkat efektivitas Program Keluarga Harapan adalah sebesar $81 \%$, dan masuk dalam kategori sangat efektif. Dampak religiositas terhadap kesejahteraan penerima bantuan Program Keluarga Harapan (PKH) pada masyarakat miskin di Kabupaten Solok, dengan menggunakan uji korelasi pearson product moment menunjukkan bahwa terdapatnya dampak religiositas terhadap program yaitu sebesar 0.875. Ini berarti religiositas berdampak terhadap kesejahteraan penerima Program Keluarga Harapan (PKH) dan tingkat hubungannya dikategorikan sangat kuat. Kemudian untuk tingkat signifikansi, nilai $r$ hitung lebih besar dari nilai $r$ tabel $(0.875>0,207)$ maka terdapat dampak antara variabel religiositas dengan variabel Program Keluarga Harapan. Dari hal diatas terdapat hubungan yang positif signifikan antara religiositas dengan kesejahteraan masyarakat miskin yang tinggal di Kabupaten Solok. Hasil penelitian menunjukkan, bahwa PKH ini akan lebih efektif jika diberikan kepada calon penerima yang mempunyai nilai religiositas yang tinggi, dan sebaiknya instansi yang memberikan bantuan harus bisa menseleksi penerima agar bantuan ini benar-benar dimanfaatkan dengan baik oleh penerima.

\section{DAFTAR PUSTAKA}

Andira, A., Burhanudin, \& Kalalinggi, R. (2018). Pelaksanaan Program Keluarga Harapan ( Pkh ) Dalam Meningkatkan Kesejahteraan Masyarakat Kota
Samarinda. Kesmas, Jurnal Kesehatan Masyarakat NasionaleJournal Ilmu Pemerintahan , 6(4), 1439-1450.

Darajat, A. H. (2016). Pelayanan Program Pokok Posyandu di Desa Doko Kecamatan Doko Kabupaten Blitar dalam Perspektif Sosiologi Keluarga. Translitera: Jurnal Kajian Komunikasi Dan Studi Media, 4(1), 114.

https://doi.org/10.35457/translitera.v4i 1.343

Devita, W., Mabrur, F., \& Putri, A. (2021). Open Access The Effect of Recruitment , Training and Compensationon the Performance of Village Assistants in Pesisir Selatan District. 1, 245-254.

Dinas Sosial. 2009. Undang-undang Republik Indonesia No. 11 tentang Kesejahteraan Sosial.

Diyah Tri, Cornelius, L. (2020). Dampak Bantuan PKH Terhadap Masyarakat Miskin di Kelurahan Bumi Nyiur Kecamatan Wanea Kota Manado. Kebiijakan Publik, 13(2), 1-14.

Farwah, A. (2013). Faktor Sosial Terhadap Kesejahteraan Islami Keluarga Muslim di Kota Surabaya. Jurnal Ekonomi Dan Bisnis, 23(2), 154-163.

Hidayat, B., Tuhiman, H., Prawiradinata, Rudy, Sumadi, \& Pungky. (2011). Program Keluarga Harapan dan Pemanfaatan Pelayanan Kesehatan Preventif Family Hope Program and Utilization of Preventive Health Care Service. Kesmas, Jurnal Kesehatan Masyarakat Nasional, 5(5), 218-226.

Infitah, N., Sukidin, S., \& Hartanto, W. (2019). Efektivitas Program Keluarga Harapan (PKH) di Desa Sumber Kejayan Kecamatan Mayang Kabupaten Jember. Jurnal Pendidikan Ekonomi: Jurnal Ilmiah Ilmu Pendidikan, Ilmu Ekonomi Dan Ilmu Sosial, 13(2), 103. https://doi.org/10.19184/jpe.v13i2.113 
46

Marseli, Anisa. (2021). Pengaruh Dana Pihak Ketiga (DPK) dan Pembiayaan Murabahah terhadap Profit dengan Non Perfoming Financing (NPF) sebagai Variabel Intervening pada KJKS BMT di Tanah Datar AlMadãris. 2(1), 50-74.

Syamsurizal. (2021). Pengaruh Kualitas dan Religiositas terhadap Masyarakat dalam Bertransaksi dengan Bank Syariah Mandiri Pariaman. Ikhtisar jurnal pengetahuan islam. 1(1), 25-38.

Lidiana, M. (2014). Pengaruh Dan Efektifitas Bantuan Program Keluarga Harapan (Pkh) Terhadap Partisipasi Pendidikan Di Kecamatan Muara Tiga Kabupaten Pidie. Jurnal Magister Ilmu Ekonomi, 2(2), 31-38.

Muliana, S., Swandari, F., \& Effendi, M. (2020). Efektivitas dan Dampak Program Keluarga Harapan (PKH) Dalam Pengentasan Kemiskinan di Kecamatan Anjir Pasar Kabupaten Barito Kuala. Jurnal Syntax Transformation, 1(10), 749-758.

Safri, E., \& Saw, M. (2021). Fiqh AlHadis: Studi Terhadap Hadis Membaca Al-Fatihah dilakukan dengan oleh Imam Muslim. 10(1).

Schweiger, G. (2019). Religion and poverty. In Palgrave Communications (Vol. 5, Issue $1)$. https://doi.org/10.1057/s41599-0190272-3

Sofianto, A. (2020). Implementasi Program Keluarga Harapan (PKH) di Provinsi Jawa Tengah. Sosio Konsepsia, 10(1), 14-31.

https://doi.org/10.33007/ska.v10i1.209 1

Suharto, Edi; Thamrin, D. (2012). Program Keluarga Harapan (PKH): Memotong Mata Rantai Kemiskinan Anak Bangsa The Family Hope Program: Breaking
The Chains of Poverty In Our Lives. The Family Hope Program, 3(1), 1-20.

Zakiyah, Z., Saputra, E., \& Alhafiza, R. G. (2020). Rekonstruksi Pemahaman Hadis dan Sunnah Menurut Fazlur Rahman. Mashdar: Jurnal Studi AlQur'an Dan Hadis, 2(1), 19-36. https://doi.org/10.15548/mashdar.v2i1. 1294

Zulfadli, M., Hakim, L., Wendry, N., \& Saputra, E. (2021). Akulturasi Islam dan Budaya Lokal dalam Tradisi Mangaji Kamatian pada Masyarakat Lareh Nan Panjang Kabupaten Padang Pariaman. 07(01), 103-114. 